11

\title{
О влиянии анизотропной проводимости углекомпозитных материалов на параметры рупорной антенны $C$-диапазона
}

\author{
(C) Н.А. Дугин, ${ }^{1,3}$ T.М. Заборонкова, ${ }^{1,2}$ Г.Р. Беляев, ${ }^{1,3}$ Е.Н. Мясников ${ }^{3}$ \\ ${ }^{1}$ Нижегородский государственный университет им. Н.И. Лобачевского, \\ 603950 Нижний Новгород, Россия \\ ${ }^{2}$ Нижегородский государственный технический университет им. Р.Е. Алексеева, \\ 603950 Нижний Новгород, Россия \\ ${ }^{3}$ Волжский государственный университет водного транспорта, \\ 603950 Нижний Новгород, Россия \\ e-mail: ndugin@yandex.ru
}

Поступило в Редакцию 20 сентября 2020 г.

В окончательной редакции 22 октября 2020 г.

Принято к публикации 8 ноября 2020 г.

Рассмотрено влияние анизотропной проводимости композитных материалов, применяемых для изготовления антенн, на параметры антенно-фидерных СВЧ устройств. Для экспериментальной проверки возможности такого эффекта были созданы рупорные антенны $L$ - и $C$-диапазонов частот из углекомпозитных материалов различной структуры с графеносодержащим эпоксисвязующим веществом. Исследование поляризационных характеристик этих антенн показало, что наличие анизотропной проводимости стенок волноводной части рупорных антенн, изготовленных из углекомпозитных материалов, привело к изменению параметров антенн, более заметному для высокочастотных антенн $C$-диапазона.

Ключевые слова: СВЧ рупорные антенны, углекомпозитные материалы, графен, характеристики антенн, поляризация.

DOI: $10.21883 /$ JTF.2021.04.50631.273-20

\section{Введение}

В последнее время композитные метаматериалы получили широкое применение в радиотехнической области [1-5]. В антенной технике углекомпозитные материалы (УКМ) используются в основном как части высоконагруженных конструкций [6]. Активно разрабатываются и создаются различные виды радиопоглощающих графитовых материалов и покрытий для снижения отражения и поглощения электромагнитных волн $[7,8]$. Конструирование композитных антенн с графитовым покрытием для увеличения проводимости излучающей поверхности устройств было предложено в $[9,10]$. Армированные углеродным волокном полимеры, благодаря их высокой проводимости, также получили широкое применение в антенных устройствах [11-13]. Необходимость использования в антенной технике новых материалов обусловлена техническими требованиями к антенным системам, в частности, УКМ применяются для снижения веса, уменьшения температурного расширения, увеличения срока действия техники [14]. Несколько лет назад авторы работы предложили использовать УКМ с графеносодержащим связующим веществом для создания антенн и антенно-фидерных устройств (АФУ) различных конструкций в широком диапазоне частот. Был предложен способ создания рупорных УКМ антенн [15] и исследованы основные характеристики излучения рупорной антенны $L$-диапазона [16]. Затем были изготовлены дипольные и рупорные антенны на частоты от 0.2 до
$5 \mathrm{GHz}$, и исследованы их электромагнитные характеристики $[17,18]$. Показано, что основные параметры УКМ антенн (коэффициент стоячей волны - КСВ, диаграмма направленности - ДН и коэффициент усиления - КУ) практически совпадают с аналогичными параметрами их металлических аналогов. По результатам проведенных исследований был сделан вывод о применимости УКМ для создания радиочастотных устройств.

Значительный научный и практический интерес в работах по данной тематике представляет изучение влияния анизотропной проводимости УКМ, из которого изготавливались АФУ, на характеристики этих устройств. Основная цель планируемых исследований - получение АФУ с заданными параметрами за счет использования анизотропных свойств проводимости материала.

В проведенных экспериментах использовались два вида УКМ различной структуры, серийно выпускаемых в промышленных масштабах: нить и сплетенная из нее ткань. Предполагалось, что ткань за счет своей структурной конфигурации имеет изотропную проводимость, а нить при круговой намотке на заготовку-матрицу имеет контактную проводимость стенок, отличную от проводимости самой нити.

Поскольку параметры (КСВ, КУ и ДН) металлических и УКМ антенн в пределах ошибок измерений совпадали [18], для выявления влияния возможной анизотропии проводимости стенок волновода на параметры рупорных антенн были исследованы поляризационные характеристики антенн $L$ - и $C$-диапазонов $(1.6$ и $5 \mathrm{GHz})$. Антенны 
этих диапазонов частот широко используются при радиоастрономических исследованиях, а также в качестве самолетных. Одной из целей настоящей работы является также исследование степени влияния анизотропной проводимости УКМ материала на характеристики антенн различных частотных диапазонов.

Результаты измерений УКМ антенны $L$-диапазона, выполненной только из УКМ нити, подробно изложены в работе [16]. Был сделан следующий основной вывод: коэффициент эллиптичности УКМ антенны в диапазоне $1.5-1.65 \mathrm{GHz}$ находится в пределах $0.35-0.45$ и в $1.5-2$ раза меньше, чем у металлического аналога. Это обстоятельство позволяло предположить возможное наличие неизотропной проводимости УКМ стенок круглого волновода, являющегося одной их основных частей конструкции исследуемых рупорных антенн. Существующие исследования [19-22] подтверждают предположение о влиянии анизотропной проводимости метаматериалов на поляризационные характеристики антенн. Изучение поляризационных характеристик рупорных углекомпозитных антенн показало, что наличие анизотропной проводимости у стенок волноводной части УКМ антенн приводит к более заметному изменению поляризационных характеристик антенн $C$-диапазона (на рабочей частоте $5 \mathrm{GHz}$ ) по сравнению с антеннами $L$-диапазона.

\section{1. Измерение поляризационных характеристик рупорных антенн}

Для изучения влияния анизотропии проводимости материалов на параметры антенн были исследованы рупорные антенны на высокий частотный диапазон, изготовленные из УКМ различной структуры. В качестве образца-эталона была выбрана специализированная рупорная антенна на диапазон $5 \mathrm{GHz}$, изготовленная из латуни с серебряным покрытием (аналогичная по конструкции антенне $L$-диапазона). В точном соответствии с ее внутренними размерами были изготовлены заготовкиматрицы для последующей укладки на них различного УКМ. При изготовлении антенных УКМ устройств применялась нить марки Zoltek PX 35, и ткань, сплетенная из этой нити с ячейкой $20 \times 20 \mathrm{~mm}$, обладающая электрическим сопротивлением $1.55 \cdot 10^{-5} \Omega[23]$. Волокна, образующие ткань, переплетены под прямым углом. Для увеличения прочности, придания проводящих свойств связующему и фиксации углекомпозитного материала на заготовках-матрицах использовалась эпоксидная смола с добавлением графеносодержащих структур. Нить и ткань наносились на заготовку методом круговой намотки с пропиткой графеносодержащим эпоксисвязующим. После отвердевания связующего вещества заготовка извлекалась. Таким образом были получены два модельных образца УКМ рупорных антенн (из нити и ткани) диапазона $5 \mathrm{GHz}$ (рис. 1).

Для создания у антенны излучения с эллиптической поляризацией было изготовлено поляризационное

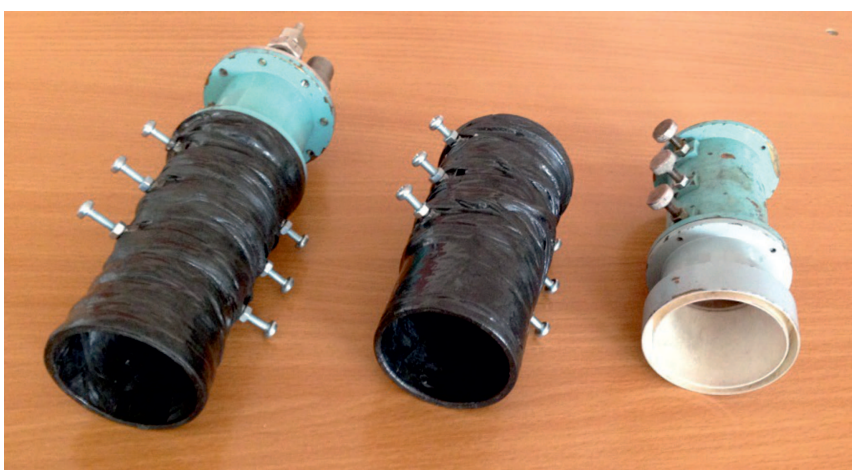

Рис. 1. Рупорные антенны $C$-диапазона с возбуждающим устройством и поляризатором из УКМ (слева и в центре) и из металла (справа).
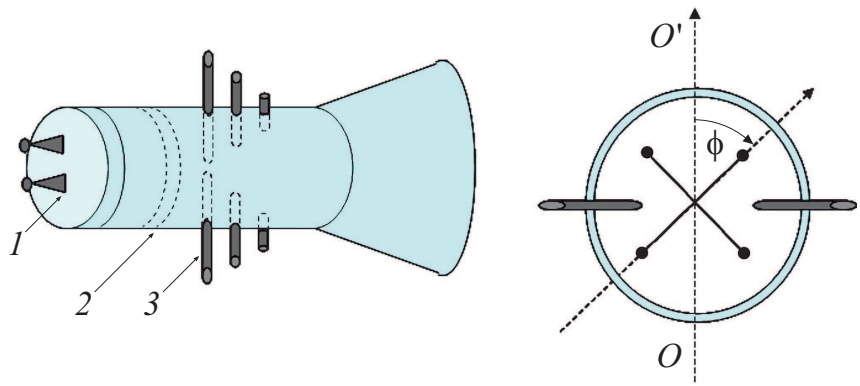

Рис. 2. Схема возбуждения и настройки рупорной антенны.

устройство для круглого волновода (волноводной части рупорной антенны); последовательный фазовый сдвиг в распространяющуюся в волноводе волну вводился с помощью шести штырей, изготовленных из латуни для всех типов антенн (рис. 2). Исследовался коэффициент эллиптичности на нескольких частотах в рабочем диапазоне антенны; предполагалось, что если анизотропия проводимости стенок волноводной части антенны имеет существенную величину, то это скажется на величине коэффициента эллиптичности волны. Причиной такого изменения коэффициента эллиптичности могут быть, например, различные величины затухания для волн левой и правой круговой поляризации, обусловленные спиральной намоткой углекомпозитных нитей.

Вид УКМ антенн на $5 \mathrm{GHz}$ с поляризаторами и их металлического аналога показан на рис. 1; схема узлов возбуждения и настройки антенн приведена на рис. 2. Возбуждающее устройство 1 состоит из двух ортогональных диполей, повернутых на $45^{\circ}$ относительно штырей поляризатора 3. Вид антенны вдоль оси волновода показан на рис. 2 (справа); отсчет угла $\phi$ при измерениях проводился от вертикальной линии $O O^{\prime}$. Для предварительной (без штырей) настройки антенн использовались согласующие пластины из оргстекла 2 , расположенные между диполями и первыми штырями поляризатора. 


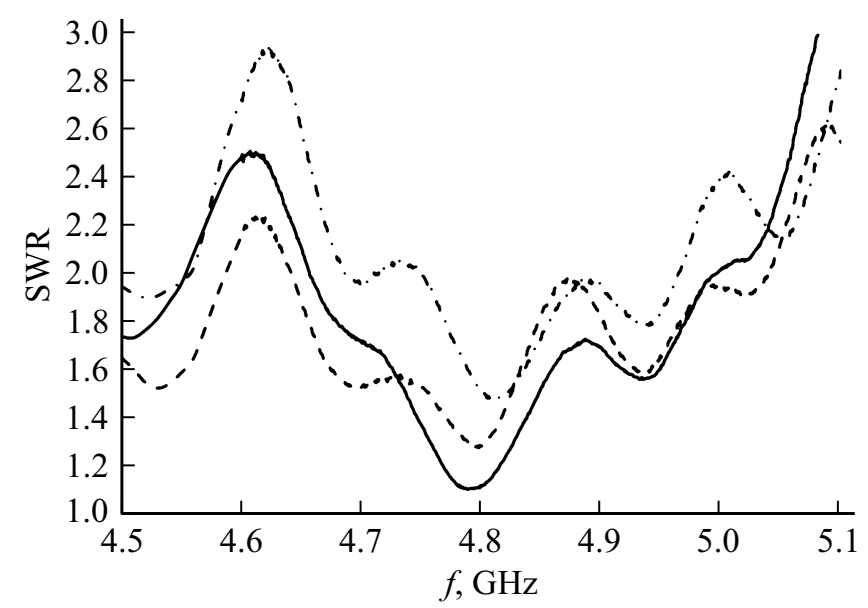

Рис. 3. Частотная зависимость КСB (SWR) исследуемых антенн. Сплошная линия - металлическая антенна, штриховая линия - УКМ антенна из ткани, штрихпунктирная линия УКМ антенна из нити.

Настройка поляризатора выполнялась установкой штырей в положения, определяемые параметрами волновода [24]. После этого подстройка КСВ не проводилась. Измерения характеристик антенн проводились для двух поляризаций волн П1 и П2, соответствующих двум ортогонально расположенным диполям (возбуждающим элементам). На рис. 3 приведены графики зависимости КСВ от частоты для трех типов антенн на поляризации П1. Из представленных данных видно, что в диапазоне частот $4.5-5.1 \mathrm{GHz}$ характеристики всех антенн оказались близки.

Металлический рупор имеет наилучший показатель $\mathrm{KCB}=1.10$ на частоте $4.79 \mathrm{GHz}$, УКМ антенна из ткани показывает минимальное значение КСВ $=1.27$ для частоты $4.80 \mathrm{GHz}$, а антенна из нити - 1.47 для частоты $4.81 \mathrm{GHz}$. Некоторое ухудшение показателя КСВ для углекомпозитных антенн может быть вызваношероховатостью рабочей поверхности антенны и наличием контактных сопротивлений в соединениях УКМ-металл. Далее на основании частотной зависимости КУ был определен рабочий диапазон частот антенн (по спаду КУ менее $50 \%$ ) в интервале частот $4.5-4.9 \mathrm{GHz}$, и все исследования поляризационных параметров проводились именно для этого диапазона.

Частотная зависимость КСВ для обеих поляризаций практически одинакова. Однако, как будет показано в разд. 2, поляризационные параметры (коэффициент эллиптичности $K_{e l l}=\left(E_{\min } / E_{\max }\right)^{2}$ и ориентация большой оси эллипса поляризации) имеют на разных поляризациях заметные отличия. Это обусловлено, главным образом, не идентичностью положения перекрестных диполей возбуждающего устройства 1 относительно отражающей стенки волновода.

Для исследования поляризационных характеристик всех антенн в качестве излучателя использовалась эталонная рупорная антенна П6-23А, запитываемая от генератора R\&S SMB100A. Исследуемые антенны устанавливались на штатном опорно-поворотном устройстве эталонной антенны с возможностью вращения антенн относительно своей оси (вращалась только излучающая антенна). Величина принятого сигнала фиксировалась измерителем мощности Я2М-66 с термоэлектрической головкой. Полученные зависимости выходного сигнала от угла поворота аппроксимировались синусоидальной функцией и нормировались.

\section{2. Поляризационные характеристики УКМ антенн}

Результаты измерений поляризационных параметров металлической антенны-аналога представлены для поляризаций П1 и П2 на рис. 4 и 5 в декартовой (рис. 4, $a$, $5, a)$ и полярной (рис. $4, b, 5, b$ ) системах координат соответственно.

Из приведенных на рисунках данных видно, что для антенны из металла наблюдается зависимость коэффициента эллиптичности волны от значения рабочей частоты. На первой поляризации наибольшее его значение составляет 0.53 на частоте $4.9 \mathrm{GHz}$, на второй поляризации коэффициент эллиптичности достигает значения, близкого к единице. На рис. 5 заметно смещение направления большой оси эллипсов поляризации (в пределах $30^{\circ}$ ).

Поляризационные характеристики УКМ антенны, изготовленной из ткани, для поляризации П1 представлены на рис. 6, для поляризации П2 - на рис. 7 в декартовой (рис. $6, a, 7, a$ ) и полярной (рис. $6, b, 7, b$ ) системах координат.

Для УКМ антенны, изготовленной из ткани, на первой поляризации параметры близки к параметрам металлической антенны. Наблюдается изменение коэффициента эллиптичности волны при изменении рабочей частоты, наибольшее его значение 0.43 на частоте $4.6 \mathrm{GHz}$. Смещение направления большой оси эллипса на рис. 6 менее заметно (порядка $10-15^{\circ}$ ), чем на рис. 5. Этот факт также является подтверждением наличия влияния анизотропии проводимости на поляризационные параметры исследованных антенн.

На второй (ортогональной) поляризации коэффициент поляризации слабо зависит от частоты и близок к идеализированому значению (т. е. единице) - изменяется всего лишь в пределах 0.7-0.85 во всем исследуемом диапазоне частот.

Поляризационные характеристики УКМ антенны, изготовленной из нити, для поляризации П1 представлены на рис. 8, для поляризации П2 - на рис. 9, так же, как и на рис. 4-7, в декартовой и полярной системах координат. Видно, что на обеих поляризациях коэффициент эллиптичности почти не зависит от частоты. Причем на П1 поляризация волны практически линейная, на П2 значение $K_{\text {ell }}$ также мало и лежит в пределах 0.35-0.45. Смещение направления большой оси эллипса поляризации - наименьшее из всех вариантов антенн. 

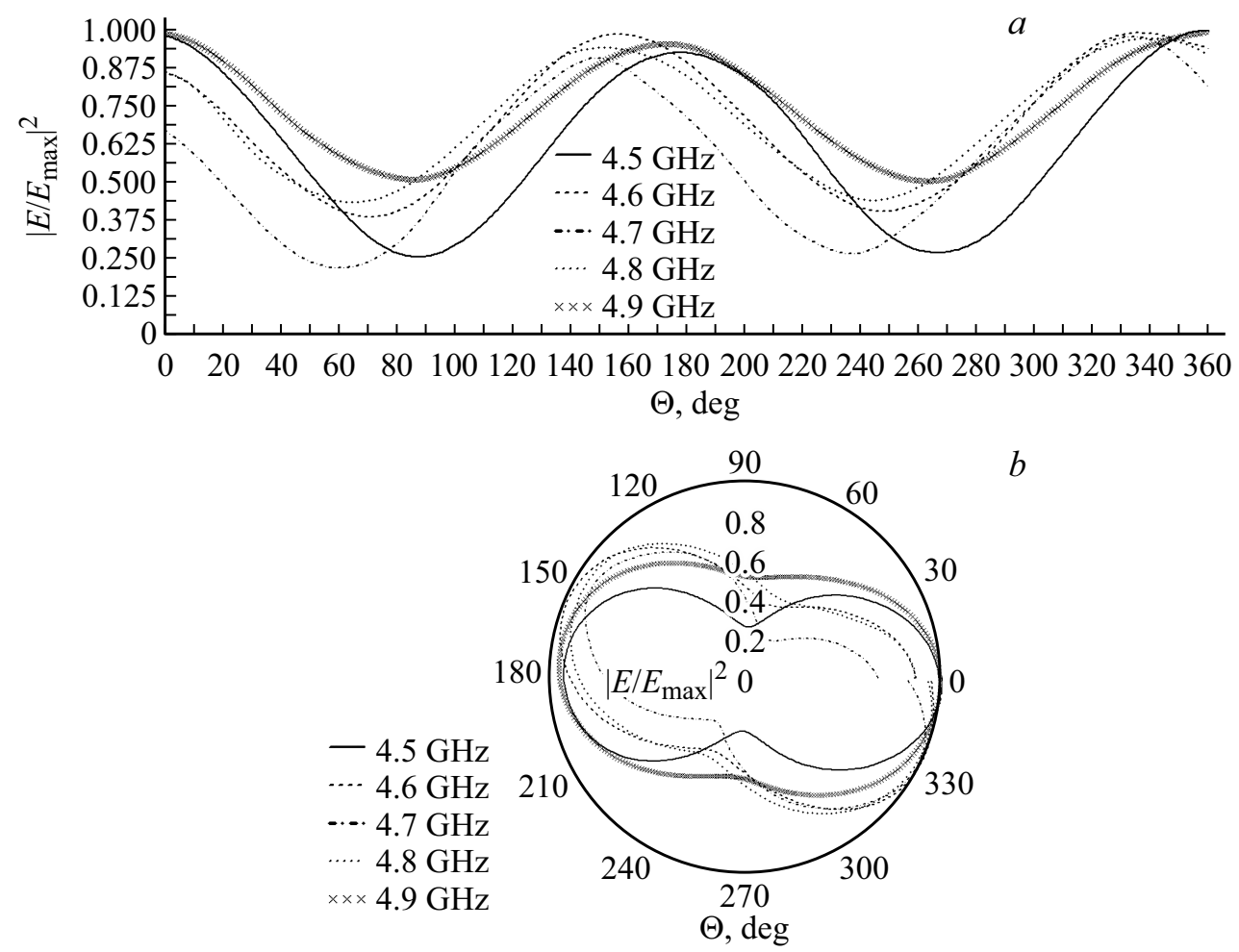

Рис. 4. Зависимость величины сигнала металлической антенны для поляризации П1 от угла поворота излучающей антенны относительно продольной оси для пяти частот в рабочей зоне в декартовой $(a)$ и полярной $(b)$ системах координат.
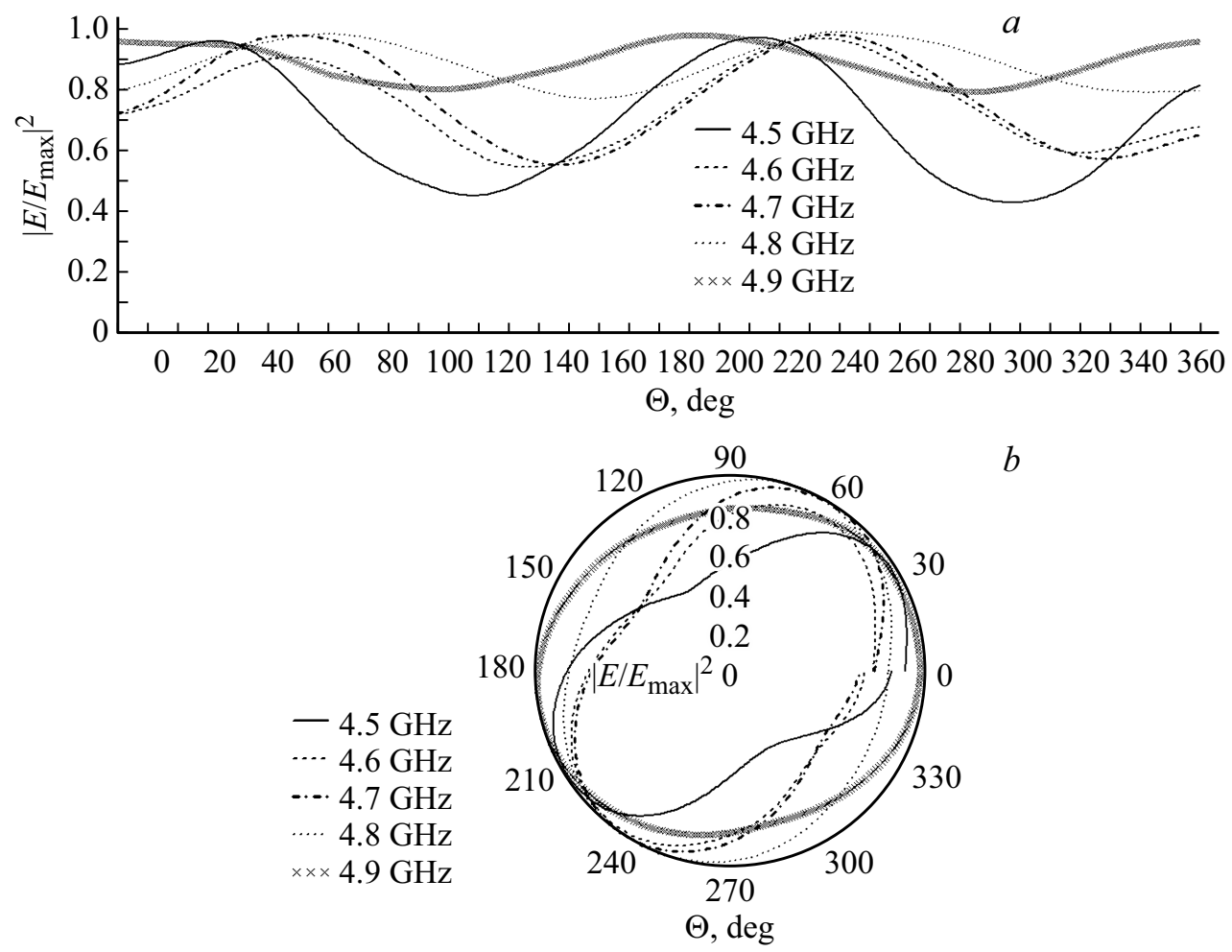

Рис. 5. Зависимость величины сигнала металлической антенны для поляризации П2 от угла поворота излучающей антенны относительно продольной оси для пяти частот в рабочей зоне в декартовой $(a)$ и полярной $(b)$ системах координат. 

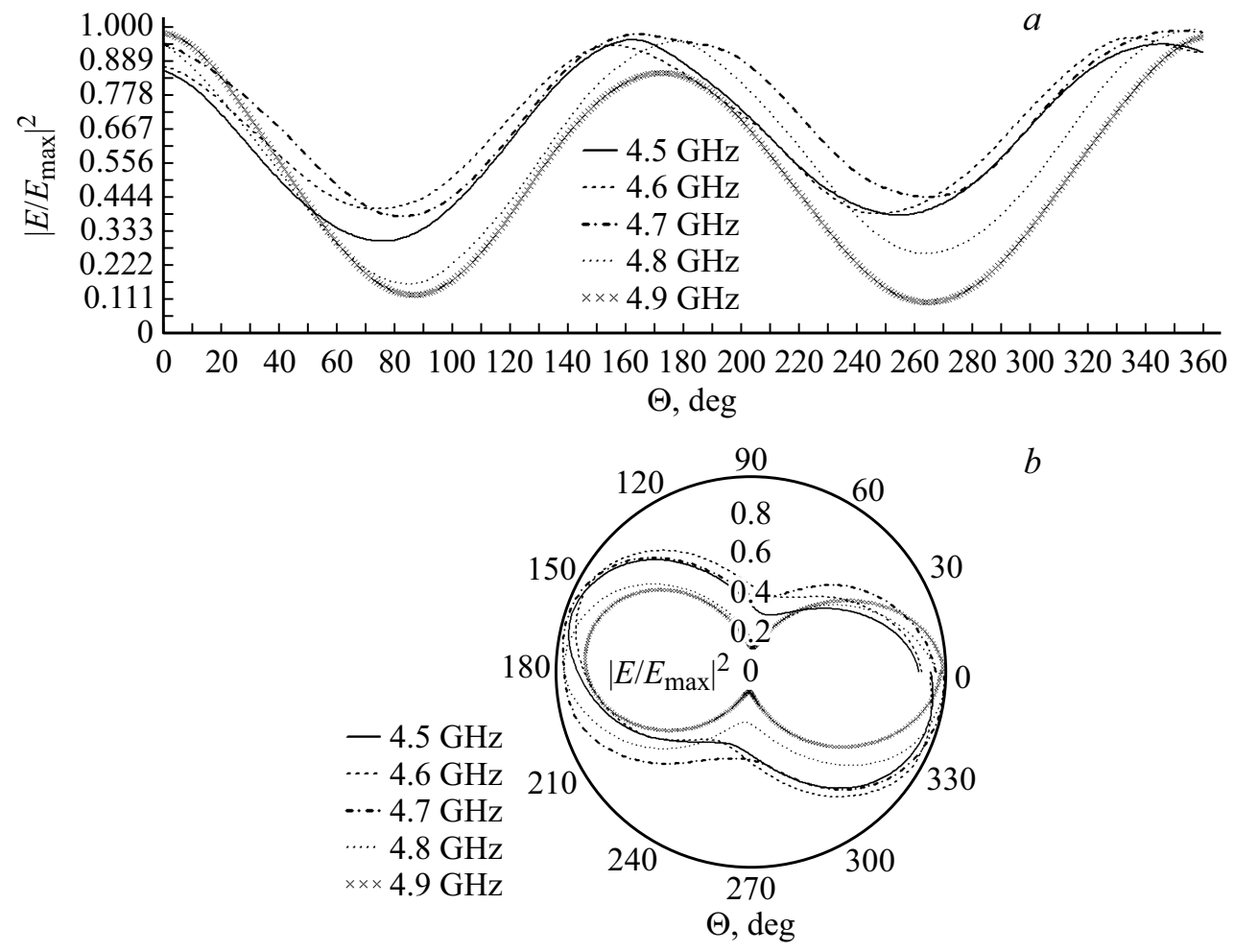

$b$

Рис. 6. Зависимость величины сигнала УКМ антенны из ткани на П1 от угла поворота излучающей антенны относительно продольной оси для пяти частот в рабочей зоне в декартовой $(a)$ и полярной $(b)$ системах координат.
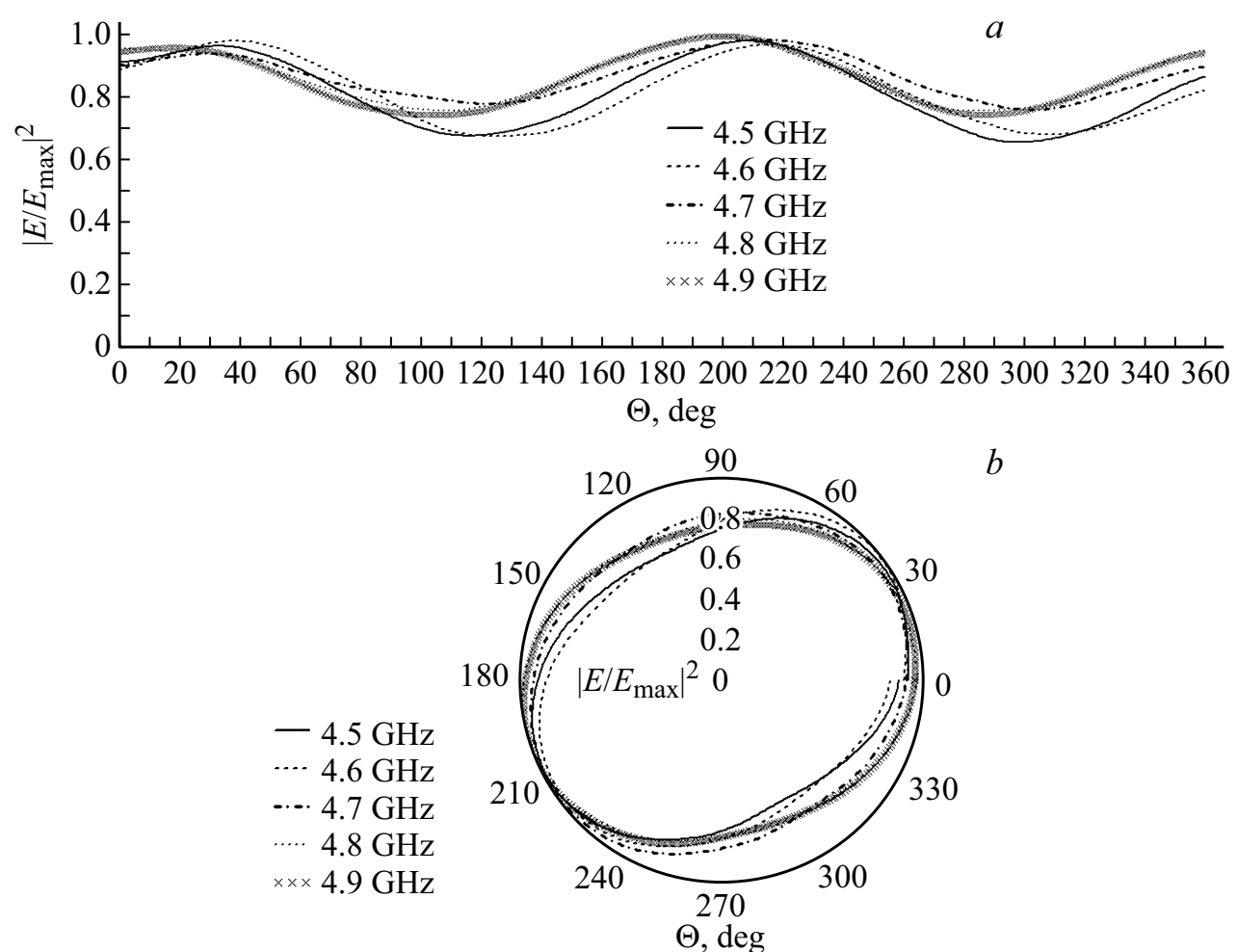

Рис. 7. Зависимость величины сигнала УКМ антенны из ткани на П2 от угла поворота излучающей антенны относительно продольной оси для пяти частот в рабочей зоне в декартовой $(a)$ и полярной $(b)$ системах координат. 

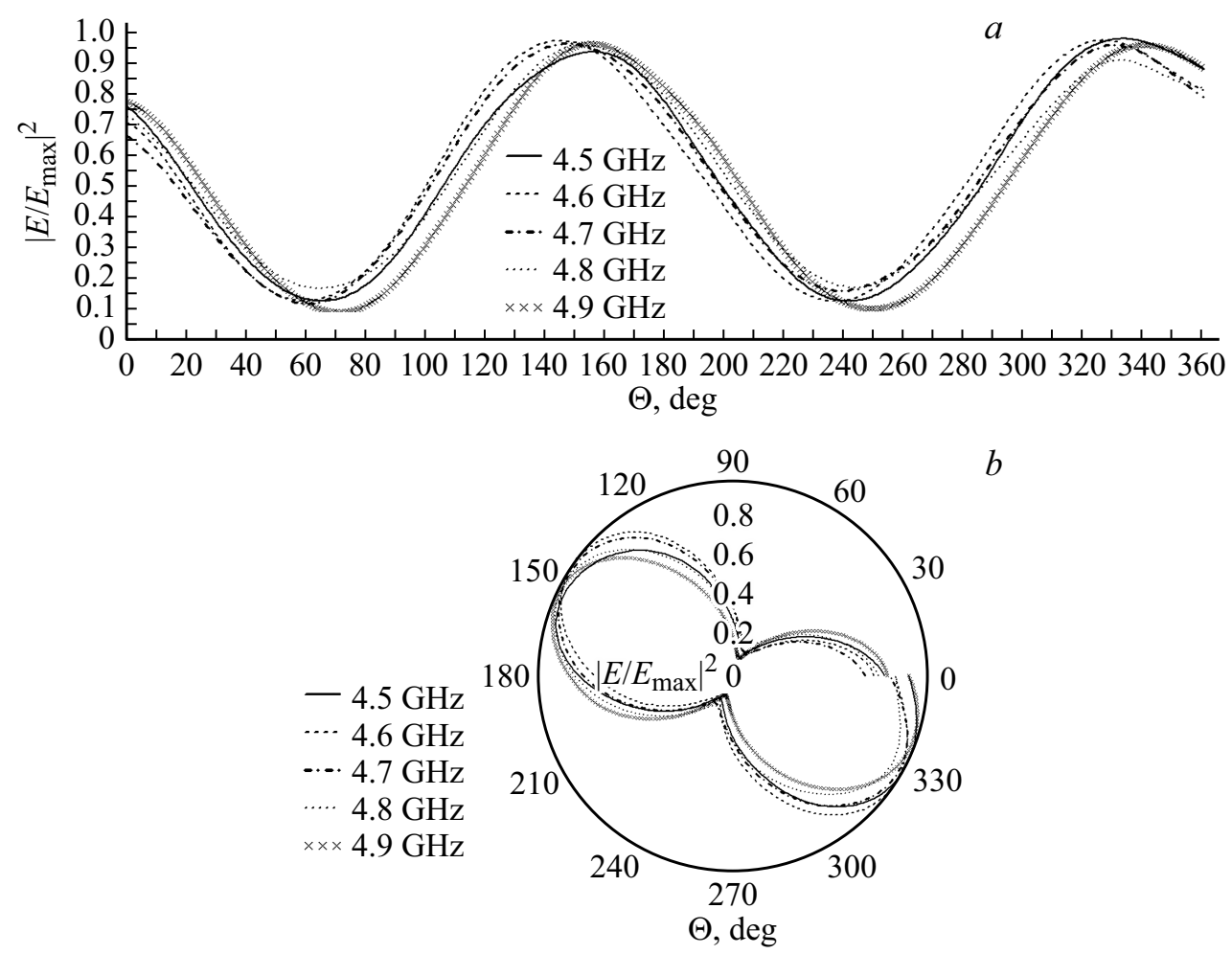

Рис. 8. Зависимость величины сигнала УКМ антенны из нити для поляризации П1 от угла поворота излучающей антенны относительно продольной оси для пяти частот в рабочей зоне в декартовой $(a)$ и полярной $(b)$ системах координат.
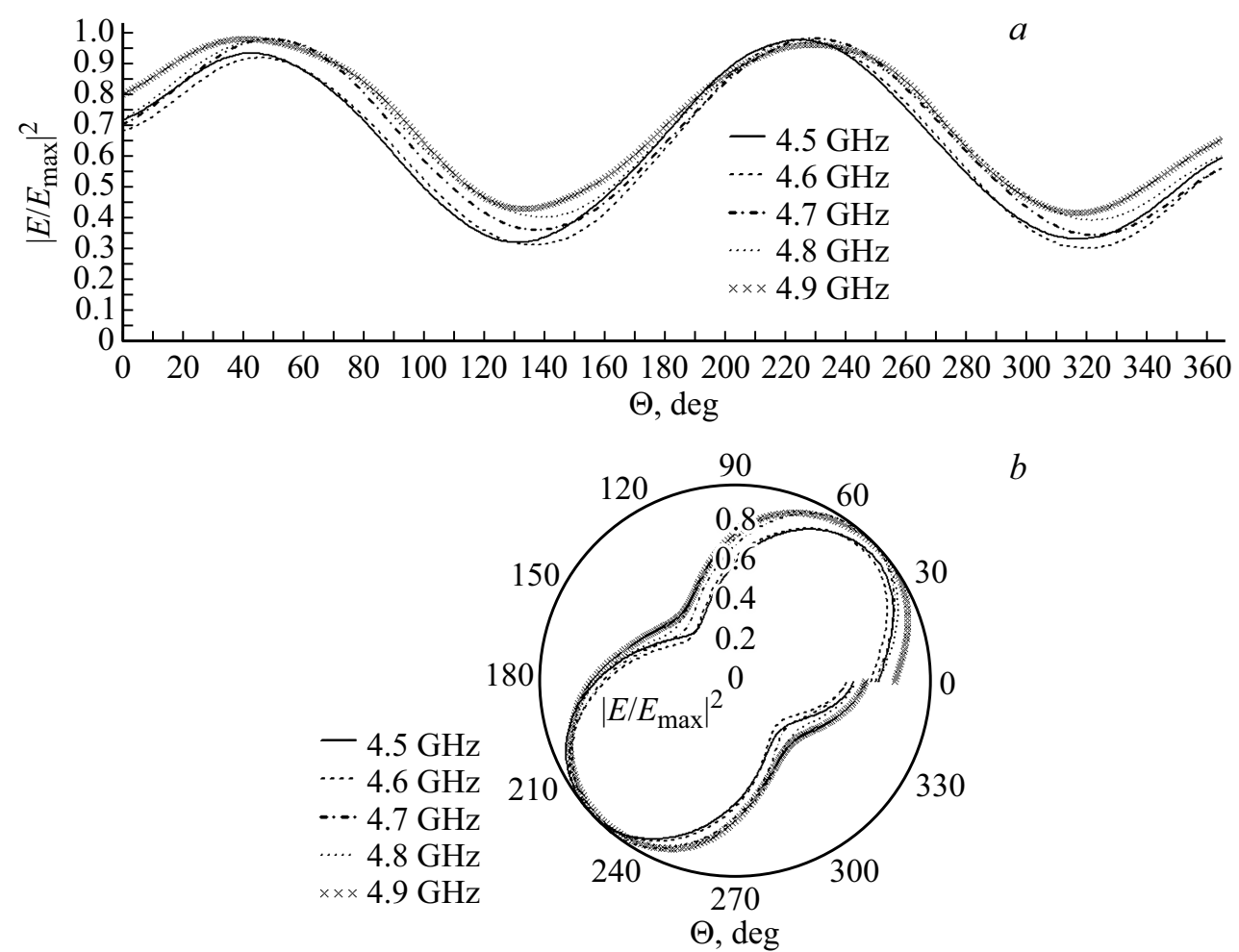

$b$

Рис. 9. Зависимость величины сигнала УКМ антенны из нити для поляризации П2 от угла поворота излучающей антенны относительно продольной оси для пяти частот в рабочей зоне в декартовой $(a)$ и полярной $(b)$ системах координат. 
Данный эффект предположительно может быть вызван недостаточной проводимостью эпокси-связующего вещества и, как следствие, увеличением контактных сопротивлений между отдельными витками в намотке рабочей поверхности волноводной части рупорной антенны.

Следует отметить, что для УКМ антенны $L$-диапазона $(1.6 \mathrm{GHz})$, изготовленной из нити по такой же технологии, поляризационные характеристики аналогичны характеристикам исследованной здесь антенны $C$ диапазона [13].

На рис. 10 представлены результаты, отражающие частотную зависимость коэффициентов усиления (максимумов интенсивности принятого сигнала) всех трех антенн на двух поляризациях. Видно, что на частотах, на которых усиление максимально, КУ УКМ антенн сдвинуты в сторону более низких частот примерно на $(0.2-0.3) \mathrm{GHz}$ на обеих поляризациях, причем УКМ антенны имеют одинаковые параметры независимо от материала изготовления.

Можно предположить, что это смещение рабочей зоны вызвано шероховатостью рабочей поверхности и незначительными отклонениями в геометрических размерах полученных УКМ образцов из-за несовершенства лабораторного оборудования при изготовлении УКМ антенн.

На рис. 11 представлены обобщенные результаты, характеризующие зависимость от частоты коэффициентов эллиптичности всех трех антенн на двух поляризациях. Видно, что и здесь на первой поляризации максимум $K_{e l} l$ УКМ антенн из ткани сдвинут относительно максимума $K_{\text {ell }}$ антенны-аналога в сторону более низких частот. Для УКМ антенны из нити $K_{\text {ell }}$ вообще не зависит от частоты. На второй поляризации величина $K_{e l l}$ для всех антенн также практически не зависит от частоты, но параметры только УКМ антенны из ткани близки к параметрам металлического аналога.

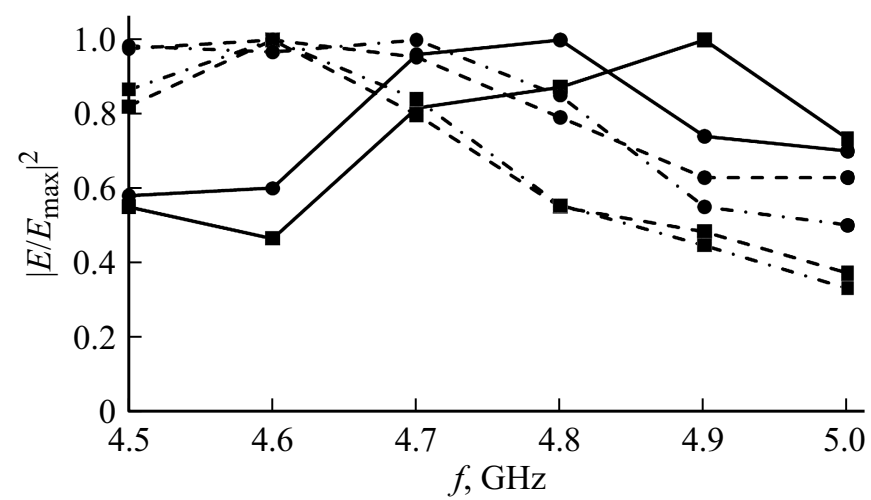

Рис. 10. Нормированный КУ для трех типов антенн в зависимости от частоты для поляризаций П1 (кривые, отмеченные квадратными маркерами) и П2 (кривые, отмеченные круглыми маркерами). Сплошная линия - металлическая антенна, штриховая линия - УКМ антенна из ткани, штрихпунктирная линия - УКМ антенна из нити.

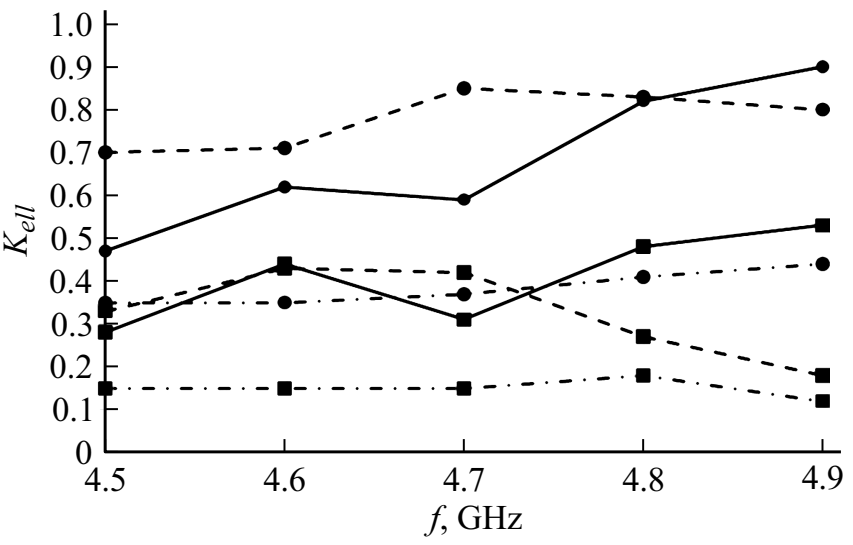

Рис. 11. Коэффициент эллиптичности для трех типов антенн в зависимости от частоты для поляризаций П1 (кривые, отмеченные квадратными маркерами) и П2 (кривые, отмеченные круглыми маркерами). Сплошная линия - металлическая антенна, штриховая линия - УКМ антенна из ткани, штрихпунктирная линия - УКМ антенна из нити.

Для продолжения работ в данном научном направлении, в первую очередь, необходимо разработать рекомендации по технологии изготовления требуемых АФУ из УКМ, а также технологию создания УКМ материала с существенно неизотропной проводимостью. В описанных экспериментах в эпокси-связующее вещество просто добавлялся графеновый порошок, что приводило к хаотическому расположению графеновых структур. Авторами был проведен эксперимент, в котором графеновые структуры в виде тонких пленок предварительно помещались в электрическое поле для придания им определенной ориентации, а, следовательно, искусственному созданию анизотропии проводимости. После этого были исследованы поляризационные свойства графеносодержащих пленок в зависимости от концентрации связующего вещества в сантиметровом диапазоне длин волн $(3-10 \mathrm{~cm})$. Было установлено, что коэффициент поляризации отраженного в обратном направлении сигнала при повороте пленки на $90^{\circ}$ составлял $(20-30) \%$ в зависимости от концентрации вещества. Отметим, что проводимость углекомпозитного материала в указанном частотном диапазоне может достигать $10^{6} \mathrm{~S}^{-1}$.

\section{Выводы}

Таким образом, поляризационные характеристики рупорных антенн в диапазоне $5 \mathrm{GHz}$, выполненных из материалов с заведомо изотропной проводимостью (таких как металл и УКМ ткань), близки как качественно, так и количественно. Определенные различия вызваны, видимо, небольшими конструктивными особенностями, которые были неизбежны в лабораторных технологических условиях. Применение промышленных технологий изготовления УКМ устройств должно свести к минимуму различия в их радиочастотных параметрах. 
Поляризационные характеристики рупорных антенн на частотах 1.6 и $5 \mathrm{GHz}$, выполненных из материала с возможной анизотропией проводимости стенок волноводов (УКМ нить с графеносодержащим эпоксисвязующим веществом), имеют заметные отличия от аналогичных характеристик антенн со стенками с изотропной проводимостью. В данном эксперименте это привело к искажению параметров стандартного поляризационного устройства (отсутствию или изменению процесса вращения фазы, распространяющейся в волноводе волны).

\section{Финансирование работы}

Экспериментальная часть работы поддержана Министерством науки и высшего образования РФ в рамках ФЦП „Исследования и разработки по приоритетным направлениям развития научно-технологического комплекса России на 2014-2020 годы“ (уникальный идентификатор проекта RFMEFI62020X0003, номер соглашения 075-15-2020-529). Обработка экспериментальных данных и анализ результатов выполнены при поддержке Российского научного фонда (проект № 20-12-00114).

\section{Конфликт интересов}

Авторы заявляют, что у них нет конфликта интересов.

\section{Список литературы}

[1] И.Б. Вендик, О.Г. Вендик. ЖТФ, 83 (1), 3 (2013). [I.B. Vendik, O.G. Vendik. Tech. Phys. 58 (1), 1 (2013). DOI: $10.1134 / \mathrm{S} 1063784213010234]$

[2] В. Слюсар. Электроника: НТБ, 7, 70 (2009).

[3] E. Lier. IEEE Ant. Prop. Mag., 52 (2), 31 (2010). DOI: 10.1109/MAP.2010.5525564

[4] M. Lashab, H.I. Hraga, A.A. Read, C. Zebiri, F. Benabdelaziz, M.R. Jones. PIERS Online, 7, 161 (2011). DOI: 10.1109/ICMCS.2014.6911410

[5] R.B. Hwang, H.W. Liu, C.Y. Chin. Progress in Electromagnetics Research (PIER), 93, 255 (2009).

DOI: 10.2528/PIER09050606

[6] Н.А. Тестоедов, В.В. Двирный, В.Е. Косенко, В.И. Лавров, Р.П. Туркенич, С.М. Роскин, А.А. Анкудинов, Г.И. Овечкин, Г.В. Двирный, Л.В. Долгов, В.В. Голованова, Д.Е. Курбатов, В.А. Бартенев, А.И. Величко. Трансформируемая антенна зонтичного типа космического аппарата. Патент № RU2427949. 2011-04-20.

[7] И.Б. Бычков, И.С. Зотов, А.А. Федий. Письма в ЖТФ, 37 (14), 90 (2011).

[8] Н.Е. Казанцева, Н.Г. Рывкина, И.А. Чмутин. Радиотехника и электроника, 48 (2), 196 (2003). [N.E. Kazantseva, N.G. Ryvkina, I.A. Chmutin. J. Commun. Technol. Electron., 48 (2), 173 (2003).]

[9] Y. Chung-Yen. Method of forming antenna by utilizing graphene. US Patent N-US2013/0004658 (A1), 2013-01-03.

[10] Choi Choon Gi; Oh Sang Soon. Metamaterial and manufacturing method at the same. US Patent $\mathrm{N}$ US2012/013989 (A1), 2012-01-25.
[11] G. Artner, P.K. Gentner, J. Nicolics, C.F. Mecklenbräuker. Intern. J. Antennas and Propagation, 2017, Article ID 6152651, 11 p. (2017). DOI: 10.1155/2017/6152651

[12] A. Scida, S. Haque, E. Treossi, A. Robinson, S. Smerzi, S. Ravesi, S. Borini, V. Palermo. Mater. Today, 21 (3), 223 (2018). DOI: 10.1016/j.mattod.2018.01.007

[13] G. Artner, R. Langwieser, C.F. Mecklenbräuker. Carbon fiber reinforced polymer as antenna ground plane material up to 10 GHz. 2017 11th European Conference on Antennas and Propagation (EUCAP) (Paris, 2017), p. 3601. DOI: 10.23919/EuCAP.2017.7928128

[14] В.В. Рыбин, П.А. Кузнецов, И.В. Улин, Б.В. Фармаковский, В.И. Бахарева. Вопросы металловедения, 1 (45), 169 (2006).

[15] Н.А. Дугин, Т.М. Заборонкова, Е.Н. Мясников. Письма в ЖТФ, 42 (11), 91 (2016). [N.A. Dugin, T.M. Zaboronkova, E.N. Myasnikov. Tech. Phys. Lett. 42 (6), 598 (2016). DOI: $10.1134 / \mathrm{S} 1063785016060043]$

[16] Н.А. Дугин, Т.М. Заборонкова, Е.Н. Мясников, Г.Р. Беляев. ЖТФ, 88 (2), 276 (2018). DOI: $10.21883 / J T F .2021 .04 .50631 .273-20$

[N.A. Dugin, T.M. Zaboronkova, E.N. Myasnikov, G.R. Belyaev. Tech. Phys., 63 (2), 268 (2018). DOI: $10.1134 / \mathrm{S} 1063784218020111]$

[17] Н.А. Дугин, Т.М. Заборонкова, Е.Н. Мясников, Г.Р. Беляев, В.В. Лобастов. Радиотехника и электроника, 63 (8), 790 (2018). DOI: 10.21883/JTF.2021.04.50631.273-20

[N.A. Dugin, T.M. Zaboronkova, E.N. Myasnikov, G.R. Belyaev, V.V. Lobastov. J. Commun. Technol. Electron., 63, 864 (2018), DOI: 10.1134/S1064226918080053]

[18] N.A. Dugin, T.M. Zaboronkova, C. Krafft, G.R. Belyaev. MDPI. Electron., 9, 590-1 (2020). DOI: $10.3390 /$ electronics 9040590

[19] H. Shi, J. Chen, A. Zhang, Y. Jiang. Frequenz, 67 (9-10), 271 (2013). DOI: 10.1515/freq-2012-0136

[20] A.V. Kudrin, T.M. Zaboronkova, A.S. Zaitseva, B. Spagnolo. IEEE Trans. Ant. Prop., 68, 195 (2020). DOI: $10.2528 /$ PIERC18042401

[21] С.В. Иванов, А.В. Назаров, Н.А. Чечин. Физика волновых процессов и радиотехнические системы, 14 (4), 6 (2011).

[22] С.В. Иванов, А.В. Назаров. Антенны, 6, 24 (2013).

[23] Электронный ресурс. Режим доступа: https: // zoltek.com/products/px35

[24] Н.М. Цейтлин. Методы измерения характеристик антенн СВЧ (Радио и связь, М., 1985) 